\title{
Individual variation and prior experience affect the discrimination of a brood-parasite by its subsocial beetle host
}

Received: 6 February 2004 / Revised: 8 July 2004 / Accepted: 3 August 2004 / Published online: 9 September 2004 (C) Springer-Verlag 2004

\begin{abstract}
In birds, host experience can modify response to parasites but nothing similar is known for insects. We studied two desert tenebrionid beetles, the subsocial host Parastizopus armaticeps and its obligate and ubiquitous brood-(clepto)parasite Eremostibes opacus, which mimics the host's odour spectrum. Nearly $10 \%$ of host burrows in the field $(n=214)$ remain unparasitised even after introducing E. opacus experimentally $(n=22)$. In discrimination tests, $7 \%$ of naive host beetles eject the parasite, showing individual variation in olfactory discrimination ability. To test for effects of prior breeding experience, naive ("first time") or experienced ("second time") breeders with or without prior parasite contact were confined with E. opacus at breeding onset, their behaviour recorded and parasite number counted on breeding completion. More first- than second-time breeding pairs completely excluded the parasite and second-time breeders with no prior contact with E. opacus had fewer parasites than any others. These pairs increased burrow-guarding dramatically, mostly during early reproduction, this being the best predictor of parasite number. Prolonged guarding, however, must be traded-off against other brood-care behaviours. Hence, it might pay breeding pairs to take the risk of accepting some parasites breeding within their burrow, and we expect this effect will be more pro-
\end{abstract}

Communicated by D. Gwynne

O. A. E. Rasa · D. Heg ( $)$

Abt. Ethologie, Zoologisches Institut,

Universität Bonn,

Kirschallee 1, 53115 Bonn, Germany

e-mail: dik.heg@esh.unibe.ch

Tel.: +41-31-6319151

Fax: +41-31-6319141

D. Heg

Department of Behavioural Ecology, Zoological Institute,

University of Bern,

Wohlenstrasse 50a, 3032 Hinterkappelen, Switzerland

Present address:

O. A. E. Rasa, Kalahari Trails,

P.O. Box 77, 8800 Uppington, South Africa nounced if poor feeding and digging conditions are taken into account. This might explain why apparently $90 \%$ of the $P$. armaticeps breeding burrows in the field contain at least one parasitic E. opacus.

Keywords Host-parasite interaction - Parasite discrimination - Host experience $\cdot$ Reproductive success . Tenebrionidae

\section{Introduction}

Parasites and their hosts are considered to be in a dynamic evolutionary relationship with one another, which is either regarded as an ongoing "biological arms race" (Dawkins and Krebs 1979) or an "evolutionary equilibrium" (Davies and Brooke 1989a). In the case of cleptoparasites and brood-parasites in particular, the host counter-adaptations are discriminatory and behavioural but there is little quantitative evidence, apart from studies on avian brood-parasites, that host individuals vary in their ability to recognise and evict them. The relationship between parasite and host has been especially well studied in the European cuckoo, Cuculus canorus, where a number of countermeasures to discriminate parasitic eggs, nestlings and adults have evolved (Davies and Brooke 1988, 1989a, 1989b; Røskaft et al. 2002; Grim et al. 2003). Host experience also appears to be implicated in discrimination: either an individual's prior breeding experience for cuckoos (Lotem et al. 1992, 1995; Brooker and Brooker 1996) or, in the case of cowbirds (Molothrus spp.), its prior experience with the parasite (May and Robinson 1985; Rohwer and Spaw 1988).

The majority of known insect brood-parasites associate with social insects, particularly hymenopterans (Wilson 1971). Many are olfactory mimics, either copying key odour substances of the host (Hölldobler 1971; Bergström and Tengö 1977; Howard et al. 1980; Van der Meer and Wojcik 1982; Henning 1983; Moritz et al. 1991; Fisher et al. 1993) or aquiring the host's "nest odour" after nest entry (Hölldobler and Carlin 1987; Dettner and Liepert 
1994). Food-storing Hymenoptera are particularly vulnerable to brood-parasites but most of the studies of parasite-host interactions are concerned with host discrimination by the parasite (Taylor 1974; Cane 1983; Jermy 1986; Papaj 1986; Field 1994) or the effect of the parasite on its host (Rosenheim 1987; Müller and SchmidHempel 1992; Schwammberger 1998) rather than vice versa. Hymenopteran hosts are known to respond to their parasites through nest clumping (Eickwort et al. 1977; Wcislo 1984; Larson 1986; Rosenheim 1990) or avoidance tactics (McCorquodale 1986). Evidence that individuals of a host species differ in their acceptance or rejection behaviour towards a brood-parasite, however, is rare (Küpper and Schwammburger 1995) and, for insects, nothing is known about the role of individual experience in such interactions. Scientific work on host-parasite interactions among non-social insects is even less common, and this paper intends to fill this gap.

The relationship between two closely related Kalahari desert tenebrionid beetles, the nocturnal subsocial species Parastizopus armaticeps Peringuey, and its obligate and almost ubiquitous brood-parasite Eremostibes opacus Koch (Rasa 1996) provides an ideal experimental system on which to test the hypotheses that there is individual variation in the ability to discriminate the parasite, and/or that prior experience, either with the parasite or with breeding, may influence the host's response. Both species have a lifespan of at least 2 years and may breed several times during their lives, allowing experience to be acquired. E. opacus is an olfactory mimic of $P$. armaticeps (Hein et al. 1996), which gains entrance to the host's breeding burrows, feeds, lays some of its own eggs there and then leaves, moving frequently between host burrows (Rasa 1996). Its larvae inhabit the sand layer beneath the host's food store and eat the food brought by the host beetle pair for their own offspring. This results in costs to the host both in increased foraging by the female for larval food and the production of smaller offspring, which have a reduced chance of breeding themselves (Rasa 1996). P. armaticeps has a rapid developmental cycle, approximately 40 days from breeding onset to eclosure of the last pupa, and that of E. opacus is of similar duration (Rödder 1995). The parasite must therefore gain entrance to the host's burrow early in reproduction for its own larvae to complete development before the burrow dries out (Rasa 1998b). P. armaticeps shows division of labour during offspring development; males guard the burrow entrance more frequently and longer than females. Although this guarding in both sexes has probably evolved to evict same-sex intruders (Rasa 1999), it also effectively blocks the smaller parasite's entry, burrow diameter being only slightly greater than that of the guarding beetle. Guarding beetles may also attack intruders at the burrow entrance (Lutermann 1997).

In this paper, we investigate whether $P$. armaticeps individuals differ in their ability to discriminate $E$. opacus and which factors contribute to individual variation in the vulnerability of breeding pairs to the parasite. The first part covers our field studies, where we (a) confirm the high level of parasitism by E. opacus of $P$. armaticeps burrows (Rasa 1994), and (b) by controlled introduction of E. opacus inside the burrow show that this high level might be due to a failure to evict the parasite as soon as it has successfully entered the burrow. In the second part, covering our laboratory studies, we elaborate on this finding, and (c) show that parasites are recognised and evicted near the burrow entrance, but usually accepted as soon as they are in the burrow entrance, whereas the nonmimetic tenebrionid beetle Herpiscius sp., only occasionally living in burrows of $P$. armaticeps, is always evicted. We proceed by testing the hypotheses that (d) prior experience with the parasite might affect the ability of the host to recognise and evict the parasite from the burrow, e.g. by learning to recognise the parasite from prior experience and increase the guarding duration in the next breeding attempt, or alternatively, whether (e) breeding experience affects the time a pair spends in guarding the burrow entrance, e.g. by learning how to guard the burrow effectively against any intruder irrespective of prior experience with the parasite, and thereby reduce the level of parasitism. We test these hypotheses experimentally in a two-factorial design creating breeding pairs from individual $P$. armaticeps with known life histories.

\section{Methods}

Field studies

A total of 214 unmanipulated breeding burrows of $P$. armaticeps were excavated at Twee Rivieren, Kalahari Gemsbok Park, South Africa $\left(26^{\circ} 27^{\prime} \mathrm{S}, 20^{\circ} 36^{\prime} \mathrm{E}\right)$ during December and between February and March from 1994 to 1997, and the number of E. opacus individuals, irrespective of developmental stage, counted. Differences found in the proportion of burrows parasitised could reflect differences in parasite distribution and burrow encounter rates. To control for this, 25 burrows were manipulated experimentally in December 1994. Nine to 12 adult E. opacus were introduced, three per day on successive days, to simulate a high rate of parasitic invasion. E. opacus can only be sexed by examination of their genitals under a binocular microscope, which would potentially damage these small beetles, so no attempt to introduce equal numbers of males and females was made. The parasites were introduced in the early morning to ensure that they remained within the burrow for at least $8 \mathrm{~h}$, daytime surface temperatures and humidity being lethal to these nocturnal beetles (Rasa 1997). The burrows were excavated 12-15 days later and the number of parasites recorded. By the day of excavation, only 22 of these burrows could be used for the analysis, the other 3 having collapsed or been abandoned by the beetles.

Laboratory studies

Individual variation in response to intruders

To determine whether male behaviour influenced parasite acceptance or rejection, 30 terraria consisting of $20 \times 30 \times 20 \mathrm{~cm}$ glass containers with a PVC insert $19 \times 30 \times 10 \mathrm{~cm}$ were set up. The insert was roofed with a PVC plate and placed in the glass container so that a 1-cm gap was left on one side. This gap was filled with moist Kalahari sand and a thin layer of sand spread on the roof of the insert to provide an area over which the animals could walk. Each 
terrarium had a shallow petri-dish containing fine gravel and water for the beetles to drink. Terraria were kept in a darkened room at $32-34^{\circ} \mathrm{C}$ with a reversed light cycle of $11 \mathrm{~h}$ dark: $13 \mathrm{~h}$ light, temperature and light regimes being equivalent to those of the breeding season in the field. A pair of individually marked beetles from our laboratory stock was introduced into each terrarium and supplied ad libitum with Lebeckia linearifolium (Papillionaceae) detritus, the preferred natural food. Behaviour inside the breeding burrow could be observed because beetles could only dig in the 1-cm gap between the PVC insert and the glass front. Observations were made under dim red light. All beetles used in the experiments had no prior breeding experience and had been kept in holding terraria with conspecifics. They had no previous contact with other species of beetle. Tests were started when third-stage larvae were present and the male was in guarding position, approximately $3 \mathrm{~cm}$ from the entrance, immobile and facing towards the surface. Beetles were observed for $10 \mathrm{~min}$ after introduction of the intruder species and the response of the male, whether it attacked or ignored the intruder, recorded. Intruders were presented once per pair for 10 min, with at least $24 \mathrm{~h}$ between presentations to avoid continuity effects. If no encounter occurred within the 10-min time limit or if, while inserting the intruder, the male was disturbed and retreated, the experiment was discarded.

For experiments outside the burrow (on the surface, 1-2 cm from the entrance), all pairs were presented in random order with either a live E. opacus or a live Herpiscius sp. (Scaurini), another small burrow-inhabiting tenebrionid common in the same habitat (Rasa 1998a) but with a different odour spectrum to E. opacus (Hein et al. 1996), the order being reversed in the second trial. For experiments inside the burrow entrance, pairs were again presented randomly with either a live Herpiscius sp. inserted approximately $1 \mathrm{~cm}$ into the burrow, or a live E. opacus. Pairs that were presented with E. opacus the previous day were presented with Herpiscius $24 \mathrm{~h}$ later and vice versa. To exclude differences in intruder activity on host response, Herpiscius being more active than E. opacus, the experiment above was repeated using freshly killed test beetles. Beetles were killed by first cooling them to immobility in a refrigerator at $+5^{\circ} \mathrm{C}$, and then transferring them to a freezer at $-10^{\circ} \mathrm{C}$ for $15 \mathrm{~min}$. This prevented excessive release of defensive secretions from the pygidial glands which could influence host response.

\section{The effect of prior breeding experience}

The experimental set-up was as described above using $60 \times 30 \times$ $40 \mathrm{~cm}$ terraria with $25-\mathrm{cm}$-high inserts. Individually marked beetle pairs from our controlled laboratory stock with known life histories were used. They had been housed in aggregations just before the start of the experiment, and were of approximately the same age. From this stock, breeding pairs were constructed with prior (had been breeding at least once, henceforth called "second-time breeders") or without prior breeding experience (were breeding for the first time during the experiment, called "first-time breeders"), and with or without prior experience with E. opacus, and allowed to start construction of a breeding burrow in one terrarium per pair each. When this was approximately $10 \mathrm{~cm}$ long, corresponding to the time of oviposition (Rasa 1999), six randomly selected $E$. opacus adults were introduced. Beetle pairs had the following breeding and parasite experiences: (1) first-time breeders: group 1 -no experience of E. opacus or with breeding $(n=29)$, group 2raised with $E$. opacus in the parental burrow but no prior breeding experience $(n=38)$; (2) second-time breeders: group 3-no prior contact with $E$. opacus but experienced breeders $(n=31)$, group $4-$ prior breeding experience with E. opacus in the breeding burrow, experienced breeders $(n=32)$. The sand in the terraria was removed after the host beetles had completed reproduction (emergence of the last offspring from its cocoon) and sieved to determine the number of parasites of different stages present. The total number of parasites minus the original six introduced adults was taken as a measure of success in parasitising the burrow. The number of $P$. armaticeps offspring and the time from parasite introduction until completion of the experiment were noted.
In each group, 18 terraria were selected at random and the behaviour of the animals recorded with a time-lapse video-recorder at 3 different times in larval development: P1-within $24 \mathrm{~h}$ of parasite introduction, directly after hatching of the first host larva; P2 - when the first host larva moulted into the 3rd larval stage; P3 - when the first host larva moulted into the 5th and final larval stage. Owing to technical failure, the videotape of behaviour in two group 2 burrows could not be analysed, reducing the sample size in this group to 16 . Behaviour was scored using the protocol provided by Rasa (1999), but only "guarding" and "attack on parasite" are analysed in this paper. "Guarding" was defined as an individual standing in or near the burrow entrance, head directed outside, usually with antennae erect and slowly waving (presumably to enhance olfactory performance). "Attack on parasite" was defined as biting or pushing parasite, which was only observed at the burrow entrance. The frequency and duration of burrow-guarding and number of attacks made on the cleptoparasites were recorded for both sexes and the films were analysed using the software program Observer 3.0 (Noldus, Wageningen, the Netherlands). Because guarding could be of extremely long duration, three 3-h recordings were made on sequential days for each phase and the average of these three data sets taken as representative of a pair's guarding behaviour for a particular phase. Details of the videorecorder setup used are given in Rasa (1999). Recordings were made under weak red light starting $30 \mathrm{~min}$ after onset of the dark phase, the peak activity period for both host and parasite (Rasa 1997)

\section{Data analysis}

Data were analysed using the statistical program SPSS 11.0 for Windows. Those data used for parametric tests were tested for normality with the Kolmogorov-Smirnov one-sample test before analysis. For the multiple regression analyses, data were corrected for non-linearity with log transformations and by adding the factors squared. All means are given with their standard deviations $( \pm 1$ $\mathrm{SD})$, unless otherwise indicated, and tests were two-tailed with $\alpha$ set at 0.05 .

\section{Results}

\section{Field studies}

The total number of E. opacus of different developmental stages found in control burrows ranged from 0 to 28 with a mean of $4.58 \pm 4.09(n=214), 22$ or $10.3 \%$ of the burrows containing no parasites. At the time of excavation, the manipulated burrows contained from 0 to 35 E. opacus with a mean of $9.0 \pm 8.72(n=22)$. Three of these burrows $(13.6 \%, n=22)$ contained no parasites, despite their previous introduction. No dead parasites inside the burrows were found. For analysis, control and experimental burrows were allocated to six different classes depending on the number of parasites they contained. Their percentage frequency distributions are shown in Fig. 1. Manipulated and control burrows differed significantly $\left(\chi^{2}=27.79\right.$, $d f=5, P<0.001)$. This, however, was not due to differences in the percent of burrows that contained no parasites, which was comparable under both conditions $\left(\chi^{2}=0.24\right.$, $d f=1, P=0.63$ ), but to a shift in frequency distribution for experimental burrows to those containing large parasite numbers (Brown 1974). 


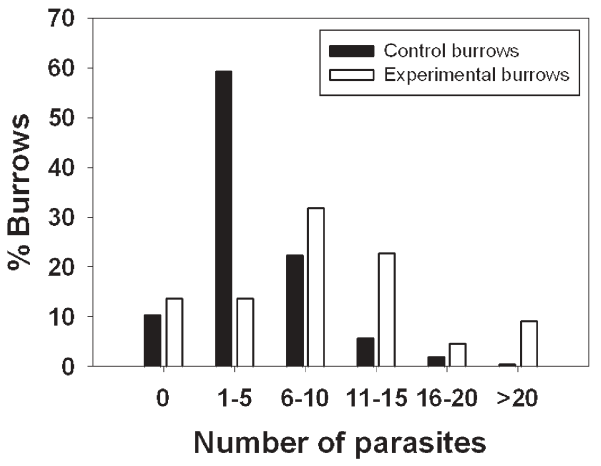

Fig. 1 The percentage of Parastizopus armaticeps burrows that contained different numbers of Eremostibes opacus under control $(n=214)$ and experimental conditions (after experimental introduction of the parasite, $n=22$ ). For clarity, burrows were assigned to different classes depending on the number of E. opacus present.

\section{Laboratory studies}

\section{Individual variation in response to intruders}

Outside the burrow entrance, intruders, independent of species, were attacked significantly more often than they were ignored. E. opacus was attacked in 22 of 24 valid trials (Binomial test, $P<0.001$ ) and Herpiscius $s p$. in 18 of 20 trials (Binomial test, $P=0.001$ ). $P$. armaticeps therefore does not discriminate between the two types of potential intruders before they attempt to enter the burrow and only $8.2 \%$ (E. opacus) versus $10 \%$ (Herpiscius) of the males confronted with an intruder do not attack it.

At the burrow entrance, live E. opacus were ignored on 23 occasions and attacked 4 times while Herpiscius sp. was attacked in all 24 valid trials. The response to intruders therefore depends on their location. Herpiscius is still attacked whether inside or outside the burrow entrance (Fishers Exact test, $P=0.52$ ) while E. opacus is mostly ignored once it enters (Fishers Exact test, $P<0.0001$ ). Dead E. opacus were attacked in 2 of 28 trials but all 26 males that encountered dead Herpiscius at- tacked them. There was no difference in the response to live or dead E. opacus (Fishers Exact test, $P=0.32$ ) or to live or dead Herpiscius (Fishers Exact test, $P=1.00$ ). The two males that attacked dead E. opacus also attacked live ones at and outside the burrow entrance. Fewer males attacked dead than live E. opacus $(7.1 \%$ vs $17.4 \%)$; thus motion may play a minor role in eliciting attack on the parasite, but Herpiscius was always attacked, independent of activity.

\section{The effects of experience}

Table 1 shows the reproductive parameters measured for the four experimental groups. Over all 130 breeding burrows, irrespective of the prior experience of the breeding pairs, 8 burrows (6.2\%) contained no E. opacus at the time of excavation. Parasites were completely excluded more often by second-time (groups 3 and 4 lumped, $11.1 \%, n=63$ ) than first-time breeders (groups 1 and 2 lumped, 1.5\%, $n=67$; Likelihood Ratio Chisquare Test, $G=5.76, d f=1, P=0.016)$. Prior experience with $E$. opacus apparently had no influence: $7.2 \%$ of the beetles without experience of the parasite rejected the parasite completely (groups 1 and 3 lumped, $n=69$ ), compared to the $4.9 \%$ of the beetles with experience (groups 2 and 4 lumped, $n=61, G=0.31, d f=1, P=0.58$ ). A Hierarchical Loglinear Model with the factors breeding experience (BRDEXP, yes or no), experience with Eremostibes parasites (ERIEXP, yes or no) and complete ejection of the parasite (EJECT, yes or no), with backward elimination of non-significant terms from the fully saturated model BRDEXP*ERIEXP*EJECT, confirmed this result: only BRDEXP*EJECT was significant $(G=5.76$, $d f=1, P=0.016$ ), whereas all other interactions were nonsignificant.

There was no difference in the reproductive success of hosts between groups (Table 1), in the number of burrows that failed to produce viable juveniles (Hierarchical Loglinear Model with backward elimination of terms

Table 1 Reproductive parameters and mean parasite attack frequency/3 h of breeding pairs in groups with differing prior breeding experience and differing prior experience with the parasite E. opacus

\begin{tabular}{|c|c|c|c|c|c|c|c|}
\hline \multirow{3}{*}{$\begin{array}{l}\text { Breeding experience: } \\
\text { Prior experience with } \\
\text { E. opacus: }\end{array}$} & \multicolumn{2}{|c|}{ 1st-time breeders } & \multicolumn{2}{|c|}{ 2nd-time breeders } & \multicolumn{3}{|c|}{ ANOVAs statistics $(F)^{\mathrm{c}}$} \\
\hline & No & Yes & No & Yes & $\begin{array}{l}\text { Breeding } \\
\text { experience }\end{array}$ & $\begin{array}{l}\text { Parasite } \\
\text { experience }\end{array}$ & Interaction \\
\hline & $(n=38)$ & $(n=29)$ & $(n=31)$ & $(n=32)$ & $d f=1$ & $d f=1$ & $d f=1$ \\
\hline $\begin{array}{l}\text { No. pairs with zero } E \text {. } \\
\text { opacus }\end{array}$ & 0 & 1 & 5 & 2 & see text & & \\
\hline No. host offspring ${ }^{\mathrm{a}}$ & $2.0 \pm 2.0$ & $2.7 \pm 2.2$ & $2.6 \pm 2.0$ & $2.3 \pm 2.1$ & 0.04 & 0.45 & 1.75 \\
\hline No. breeding failures & $12(31.6 \%)$ & $6(20.7 \%)$ & $6(19.4 \%)$ & $7(21.9 \%)$ & see text & & \\
\hline Breeding duration $^{\mathrm{a}}$ (days) & $39.9 \pm 8.6$ & $43.1 \pm 10.1$ & $41.5 \pm 6.4$ & $42.9 \pm 9.0$ & 0.23 & 2.26 & 0.37 \\
\hline $\begin{array}{l}\text { No. E. opacus/burrow }{ }^{\mathrm{a}} \mathrm{b} \\
\text { No. pairs observed }\end{array}$ & $\begin{array}{l}16.6 \pm 11.1 \\
(n=18)\end{array}$ & $\begin{array}{l}14.1 \pm 8.8 \\
(n=16)\end{array}$ & $\begin{array}{l}6.5 \pm 5.6 \\
(n=18)\end{array}$ & $\begin{array}{l}14.6 \pm 10.8 \\
(n=18)\end{array}$ & $8.36 * * *$ & $2.88^{\mathrm{d}}$ & $9.90 * * *$ \\
\hline Attack frequency/3 $\mathrm{h}^{\mathrm{a}}$ & $1.83 \pm 5.71$ & $1.88 \pm 2.75$ & $0.11 \pm 0.32$ & $0.61 \pm 1.15$ & $5.07 *$ & 1.48 & 0.003 \\
\hline
\end{tabular}

${ }^{a}$ Means with their standard deviations, and for attack frequency: square root transformation of the values +0.5 before statistical analysis.

${ }^{\mathrm{b}}$ Excluding the pairs with zero E. opacus: group 1:16.6 \pm 11.1 , group $2: 14.6 \pm 8.5$, group $3: 7.7 \pm 5.2$, group $4: 15.5 \pm 10.5$ E. opacus/burrow.

c $* P<0.05 ; * * P<0.01 ; * * * P<0.005$.

${ }^{\mathrm{d}} P=0.092$. 
from BRDEXP*ERIEXP*FAIL, where only the term failure, FAIL yes or no, was significant $G=37.4, d f=1$, $P<0.0001)$, or in the duration of the breeding periods (Table 1). The number of E. opacus present, however, significantly depended on the breeding experience and the interaction between breeding experience and prior experience with the parasite (Table 1). Second-time breeders with no prior experience of E. opacus had fewer parasites than any other group. There was a positive correlation between the number of host offspring and E. opacus (Pearson's $r=0.206, n=130, P=0.018$ ), but no correlation between breeding-period duration and parasite number ( $r=-0.071, n=130, P=0.419$ ).

Although attacks were observed relatively rarely, the attack frequency was, contrary to expectation, significantly lower for pairs with breeding experience, and did not depend on prior experience with the parasite or their interaction (Table 1). Unexpectedly, there was no relationship between the frequency with which a pair attacked and the number of E. opacus present in their burrow (Pearson's $r=0.163, n=70, P=0.18$, attack frequency +0.5 square root transformed before analysis).

Additional to directly attacking E. opacus, breeders might also deter the parasite by guarding the burrow entrance. Mean male guarding duration $/ 3 \mathrm{~h}$ over the entire breeding period did not depend on previous breeding experience (two-way ANOVA $F_{1,70}=0.53, P=0.47$ ) or prior experience with the parasite $\left(F_{1,70}=0.12, P=0.73\right)$, but on the interaction between these two factors $\left(F_{1,70}=\right.$ $8.51, P=0.005)$. This was due to males from pairs without breeding experience guarding more when previously exposed to the parasite (increase from group 1 to 2, Fig. 2a), whereas males from pairs with breeding experience showed the opposite pattern (decrease from group 3 to 4, Fig. 2a). However, although males do most of the guarding, the males' guarding effort might be modified by the guarding effort of their female partners. Summing the guarding duration of the pair again showed a highly significant interaction effect (Fig. 2a, two-way ANOVA, interaction: $F_{1,70}=10.32, P=0.002$; prior experience with parasite: $F_{1,70}=2.08, P=0.15$ ) and, additionally, pairs with breeding experience guarded significantly less (breeding experience: $F_{1,70}=5.12, P=0.027$ ).

Because the breeding cycle of E. opacus and its host are of similar length, to counteract the parasite effectively, hosts should guard most during the early part of reproduction. The mean guarding durations $/ 3 \mathrm{~h}$ of males and males plus females during P1 were compared between groups. These are shown for comparison in Fig. 2b. Males without breeding experience guarded on average $88 \mathrm{~s}$ longer (two-way ANOVA, breeding experience: $\left.F_{1,70}=4.22, P=0.044\right)$ and, contrary to expectation, with prior exposure to the parasite guarded on average $1,420 \mathrm{~s}$ shorter (prior experience with parasite: $\left.F_{1,70}=5.17, P=0.026\right)$. But again the interaction was significant $\left(F_{1,70}=5.47, P=0.022\right.$, parameter estimate for group 1: $1,440 \mathrm{~s}$ ), due to the high guarding duration of the group 3 males. Adding the guarding duration of the females did not significantly alter these results (Fig. 2b,

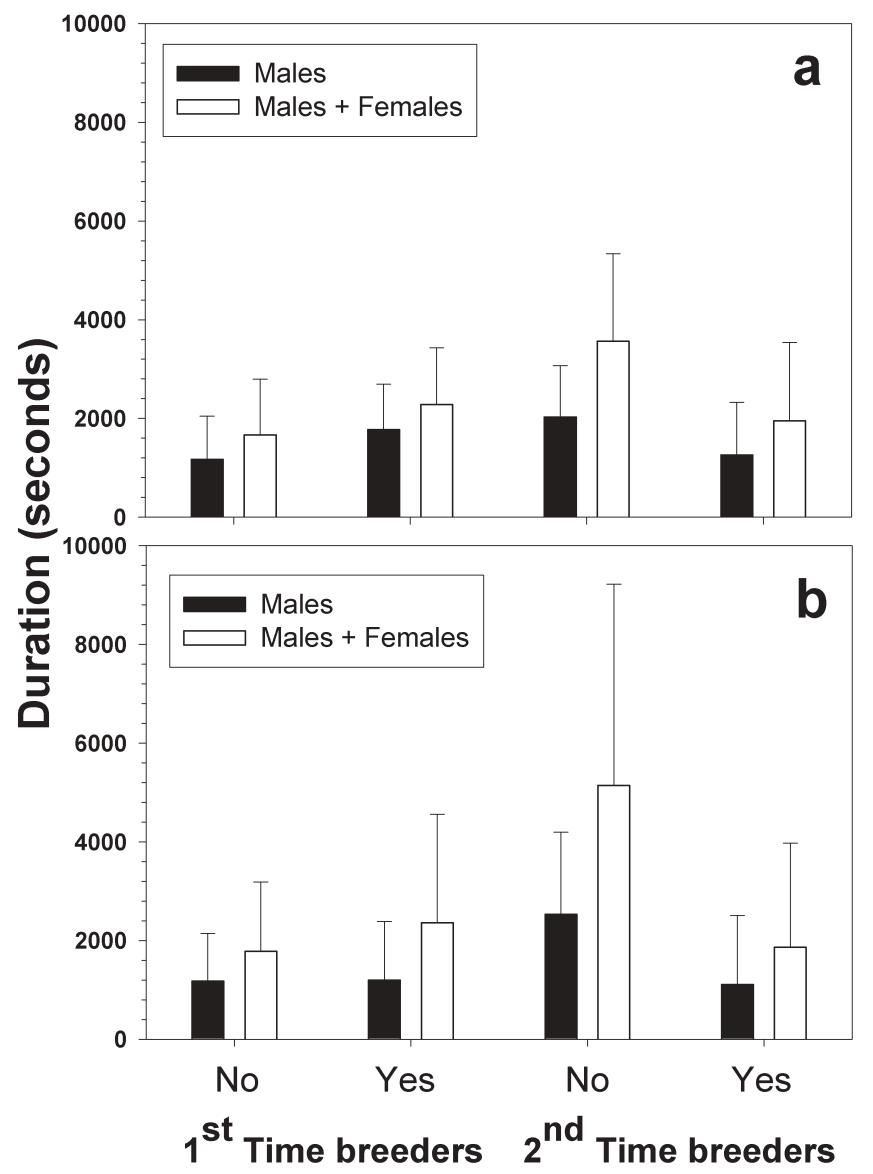

Fig. 2 The total guarding durations of males and of males and females with their standard deviations for the four experimental groups over: a the entire breeding period, and $\mathbf{b}$ early reproductive period (period 1, P1) only (No no prior parasite contact; $n=18$ and 18 for first-time and second-time breeders respectively; Yes raised with the parasite in the parental burrow; $n=16$ and 18 respectively).

two-way ANOVA, breeding experience: $F_{1,70}=5.11$, $P=0.027$, prior experience with parasite: $F_{1,70}=4.53$, $P=0.037$, interaction: $F_{1,70}=9.21, P=0.003$ ).

Several parameters have been shown to influence the number of $E$. opacus in $P$. armaticeps burrows. The results of a multiple regression analysis to determine which factors were important in predicting the number of parasites present are shown in Table 2. Data on guarding duration per pair were converted to percentages $(0-200 \%$, the sum of the male and the female), since the results suggested additive effects of male and female guarding on parasite detection (in most burrows parasites can easily enter the burrow from several sides, so guarding at several positions around the burrow entrance might be the most effective). The regression model generated showed an extremely good fit, as indicated by the resulting small residual variance (Table 2). By far the most important parameter was the length of time the breeding pair guarded during $\mathrm{P} 1$, followed by their guarding duration during P2 and P3. Both had exponential negative relationships with the number of parasites present (Fig. 3a,b). The only other significant predictor was the number of 
Table 2 Multiple regression model of the effects of attack frequency, duration of breeding, number of offspring, guarding duration of pairs during period 1 (P1), guarding P1 squared, guarding duration of pairs during period 2 plus $3(\mathrm{P} 2+\mathrm{P} 3)$, and guarding $\mathrm{P} 2+\mathrm{P} 3$ squared on the number $E$. opacus within the host breeding burrow (log-transformed, $n=70$ ). For the final model ANOVA: $F=13.682, P<0.0001$; the regression sum of squares $S S=4.015$, $d f=4$, the mean square $M S=1.004$; with residual $S S=4.768, d f=65$,
$M S=0.073$. Multiple regression was performed with backward elimination of terms: the table shows the step at which a nonsignificant variable was removed; and if significant, the partial regression coefficient $B$ with its standard error, the $t$-test statistic and its $P$-value. The model remained virtually the same, and the quadratic effect of $\mathrm{P} 1$ remained highly significant $(P=0.004)$, when the outlier on the right hand side in Fig. 3a was excluded from the analysis

\begin{tabular}{lcccc}
\hline Variable & Step & Partial $B$ & $t$ & $P$ \\
\hline Final model: & & $1.299 \pm 0.079$ & 16.497 & $<0.0001$ \\
Constant & & $0.04588 \pm 0.016$ & 2.8 & 0.007 \\
No. offspring & $-0.0169 \pm 0.003$ & -5.447 & $<.0001$ \\
\% Guarding in P1 & $0.0001176 \pm 0.00001$ & -3.018 & 0.0001 \\
\% Guarding in P1 & $-0.00677 \pm 0.002$ & -0.29 & 0.112 \\
\% Guarding in P2+P3 & & & 0.162 & 0.977 \\
Factors removed: & 1 & & 1.311 & 0.872 \\
Attack frequency & 2 & & 0.195 \\
Guarding frequency & 3 & & & \\
Breeding duration & 4 & & & \\
\% Guarding in (P2+P3) & & & & \\
\hline
\end{tabular}

host offspring in the burrow, which correlated positively with E. opacus number (Fig. 3c). Neither attack nor guarding frequency during P1 or breeding duration were useful predictors. Because offspring number was positively correlated with E. opacus number, a second multiple regression analysis was run to determine whether parental behaviour was a predictor of reproductive success. None of the variables tested against offspring number (guarding duration during P1, during P2 and P3, guarding frequency and attack frequency) had a significant effect $(P>0.05$ in all cases).

\section{Discussion}

Individual variation in host behaviour

In contrast to dung beetles (Halffter and Matthews 1966) and burying beetles (Pukowski 1933), which can protect their larval food sources after closing the entrance to their underground chambers, $P$. armaticeps has continuous provisioning of its young. The burrow entrance must therefore remain open to allow food transport. Open burrows are, in principle, continuously exploitable by both con- and interspecific intruders. This special vulnerability (but see Hanski and Cambefort 1991; Trumbo et al. 2001), together with the evolution of odour spectrum congruity between parasite and host, have contributed towards E. opacus being such a successful cleptoparasite, and nearly $90 \%$ of the breeding burrows in the field contain at least one parasite.

It is important to note that host larvae can be experimentally added, subtracted or even replaced by those of different ages, and are accepted immediately (SchmidtEisenlohr 1998, e.g. similar to many cuckoo hosts, Davies 2000, albeit indirect discrimination of cuckoo nestlings seems to play a role, see Grim et al. 2003). We have shown that the critical parasite discrimination and counteractive behaviour takes place away from the brood, near the burrow entrance (similar to many bird hosts chasing the cuckoo female from the neighbourhood of the nest, Røskaft et al. 2002). The odour congruence between $E$. opacus and its host, unlike that of brood-parasites of most other insects (but see Sledge et al. 2001), is almost complete, both in substance type and substance quantity. Indeed, there is closer congruence between the parasite and its host than between host subspecies (K. Peschke and S. Geiselhardt, unpublished data). It is therefore not surprising that, on the basis of this mimicry, E. opacus can gain entrance to such a high proportion of its host's burrows in the field.

The experimental introduction of parasites, however, did not result in all burrows being parasitised, despite the parasites being confined to the burrow for at least $8 \mathrm{~h}$. Individual differences in the host's ability to discriminate the parasite olfactorally and eject it could explain this phenomenon. Attack behaviour is a good measure of $P$. armaticeps' ability to discriminate intruders olfactorally because species with an odour spectrum differing from its own and that of the parasite were always attacked. The discrimination tests showed, however, that despite the similarities between the odour spectra of parasite and host, a small proportion of the host beetle population (7\%) is still capable of detecting E. opacus and ejecting it. That this discrimination is olfactory is supported by the fact that these individuals attacked both active and dead, motionless parasites once they had intruded into the burrow entrance and could be antennated. In contrast, attack outside the burrow seems to be indiscriminate and probably released by the intruder's motion. This can also play a part in host burrow defence at the burrow entrance because more hosts attacked live E. opacus than dead ones. Nevertheless, the rapid change in host response to the parasite, from attack to ignoring, once the parasite enters the burrow, shows that olfactory cues predominate in the discriminatory process.

Alternatively, E. opacus individuals might vary in their ability to avoid detection via their odour and behaviour, 

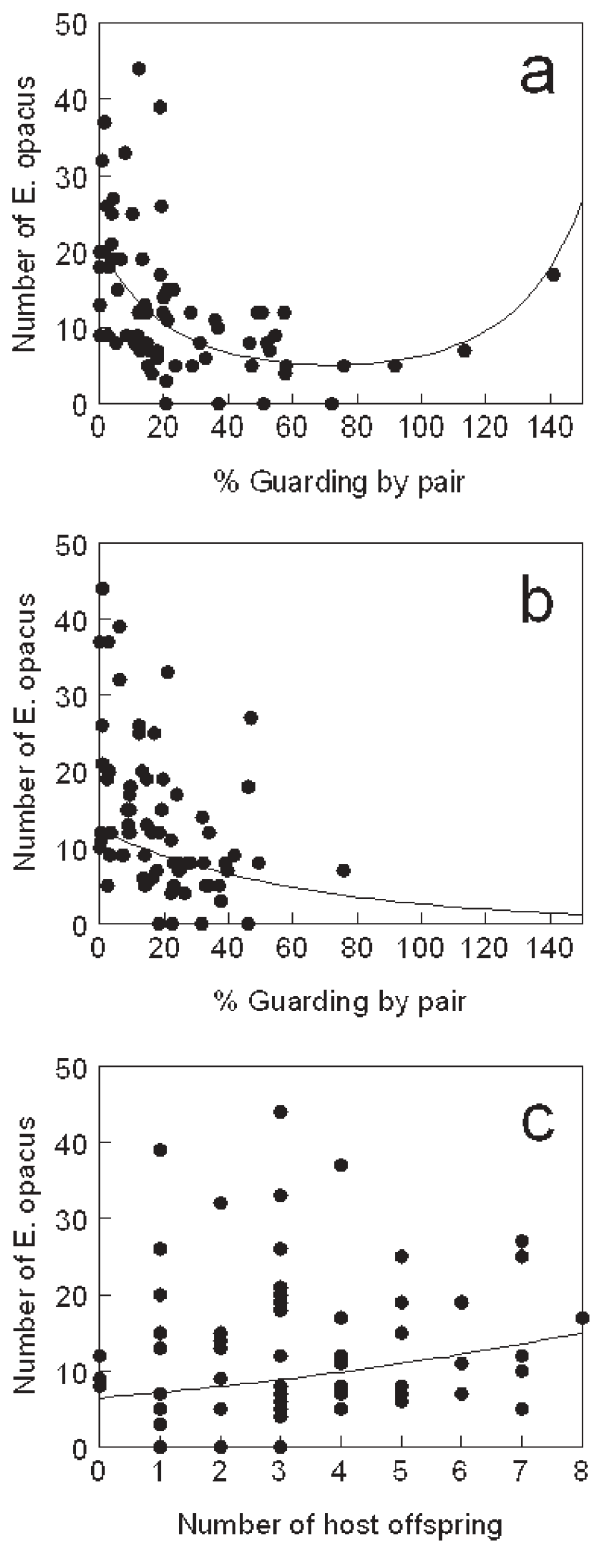

Fig. 3 The number of the parasite Eremostibes opacus present in the host burrows in relation to the percentage guarding of individual pairs (male plus female guarding added, $n=70$ ), a during early reproduction (period 1, P1), and $\mathbf{b}$ during late reproduction (periods 2 and $3, \mathrm{P} 2+\mathrm{P} 3)$. c The number of E. opacus in relation to host offspring number. All three variables significantly affected $E$. opacus number: curves show the partial effects of the variables, controlling for the average effects of the other two variables (see Table 2).

hence leading to $7 \%$ ejection of the "less adapted" individuals. Additionally, some parasites might not be willing to parasitise the burrow, and leave the burrow instead, maybe in search of higher-quality burrows to parasitise. Nevertheless, since the parasites were introduced at the best possible moment within the breeding cycle of the hosts to start parasitic breeding, this explanation is less likely to apply.
The effects of experience

Lotem et al. (1995) suggested that a learning process is involved in interactions between European cuckoos $(\mathrm{Cu}$ culus canorus) and their hosts. Inexperienced great reed warblers (Acrocephalus arundinaceus) presented with non-mimetic eggs are more likely to accept them than experienced breeders and to show lower rejection rates when encountering such eggs in the future. In contrast, bluethroats (Luscinia svevica) did not show a difference in rejection rate according to male or female age (Amundsen et al. 2002). Rothstein (1974) succeeded in getting a naive catbird (Dumetella carolinensis) to reject its own egg after sequentially replacing its eggs with model cowbird eggs.

Surprisingly, the prior experience with the parasite was found to play an insignificant role in our study system, suggesting that in general $P$. armaticeps does not learn to recognise the parasite. Rather the host's breeding experience and the interaction between breeding experience and prior experience with the parasite affected the interaction between $P$. armaticeps and E. opacus. Brooker and Brooker's (1996) findings for splendid fairy wrens were the opposite of those for $P$. armaticeps. Prior breeding experience in fairy wrens resulted in a higher rate of acceptance rather than rejection of cuckoo eggs. Although we did not find a consistent effect of prior experience with the parasite on parasitism rate in the next breeding attempt, we did find a very strong effect of guarding duration and the number of offspring on the number of $E$. opacus in the burrow. This suggests: (1) that variation in guarding behaviour for whatever reason might be a major cause for the variation in the parasitism level found in the field; (2) that a trade-off might exist between the time spent by the female guarding the burrow and collecting food and/or the time spent by the male guarding the burrow and digging to extend the burrow and track the optimal moisture level for successful offspring development. When pairs face food scarcity, rapid desiccation of the burrow or have to provide a large brood with food and space, they might need more time for other activities rather than guard the burrow against intruding parasites.

Future laboratory tests should solve these points. The major advantages of experimental laboratory studies, like ours, in contrast to most, if not all, field studies of host learning, host parasite-rejection behaviour and parasites' abilities to curb ejection are twofold. First, these studies allow full control of the individual experiences, and hence potential learning events, breeders and parasites have prior to testing. Second, the opportunity to raise multiple generations and test for genetic factors contributing to the host's and parasites' behaviour.

Acknowledgements We are grateful to Bärbel Bauch and Ute Grundtner for their tremendous input in maintaining the beetle breeding colonies and, with Gorg Masoud, running many of the laboratory experiments. We should also like to thank the National Parks Board of Southern Africa for allowing A.R. to conduct the field research at the Kalahari Gemsbok National Park. Thanks are also due to Klaus Peschke and Sven Geiselhardt for providing the 
information on the beetle olfactory spectra. The study was supported by a grant from the Deutsche Forschungsgemeinschaft to A.R. and an Alexander von Humboldt fellowship to D.H. We thank Tobias Limbourg, Klaus Peschke and six anonymous referees for their critical comments on earlier versions of the manuscript.

\section{References}

Amundsen T, Brobakken PT, Moksnes A, Røskaft E (2002) Rejection of common cuckoo Cuculus canorus eggs in relation to female age in the bluethroat Luscinia svecica. J Avian Biol 33:366-370

Bergström G, Tengö J (1977) Cleptoparasitism and odour mimetism in bees: do Nomada males imitate the odour of Andrena females? Science 196:1117-1199

Brooker MG, Brooker LC (1996) Acceptance of the splendid fairy wren of parasitism by horsfeld's bronze-cuckoo: further evidence for evolutionary equilibrium in brood parasitism. Behav Ecol 7:395-407

Brown MB (1974) Identification of the sources of significance in two-way contingency tables. Appl Stat 23:405-413

Cane JH (1983) Olfactory evaluation of Andrena host suitability by kleptoparasitic Nomada bees (Hymenoptera:Apoidea). Anim Behav 31:138-144

Davies NB (2000) Cuckoos, cowbirds and other cheats. Poyser, London

Davies NB, Brooke M de L (1988) Cuckoos vs. reed warblers: adaptations and counter-adaptations. Anim Behav 36:262-284

Davies NB, Brooke M de L (1989a) An experimental study of coevolution between the cuckoo Cuculus canorus and its hosts. I. Host egg discrimination. J Anim Ecol 58:207-224

Davies NB, Brooke M de L (1989b) An experimental study of coevolution between the cuckoo Cuculus canorus and its hosts. II. Host egg markings, chick discrimination and general discussion. J Anim Ecol 58:225-236

Dawkins R, Krebs JR (1979) Arms races between and within species. Proc R Soc Lond B 205:489-511

Dettner K, Liepert C (1994) Chemical mimicry and camouflage. Annu Rev Entomol 39:129-154

Eickwort GC, Eickwort KR, Linsley EG (1977) Observations on the nest aggregations of the bees Diadasia olivacea and D.diminuta (Hymenoptera: Anthrophoridae). J Kans Entomol Soc 50:1-17

Field J (1994) Selection of host nests by intraspecific nest parasitic digger wasps. Anim Behav 28:113-118

Fisher RM, Greenwood DR, Shaw GJ (1993) Host recognition and the study of a chemical basis for attraction by cuckoo bumble bees (Hymenoptera, Apidae). J Chem Ecol 19:771-786

Grim T, Kleven O, Mikulica O (2003) Nestling discrimination without recognition: a possible defence mechanism for hosts towards cuckoo parasitism? Proc R Soc Lond B [Suppl]270: $73-75$

Halffter G, Matthews E (1966) The natural history of dungbeetles of the subfamily Scarabaeinae (Coleoptera:Scarabaeinae). Folia Entomol Mex 12-14:1-312

Hanski I, Cambefort Y (1991) Dung beetle ecology. Princeton University Press, Princeton

Hein E, Rasa OAE, Ockenfels P (1996) Odour profile congruity in two closely related desert tenebrionid beetles: homology as the basis for a cleptoparasitic relationship? Chemoecology 7:15616

Henning SF (1983) Chemical communication between lycaenid larvae (Lepidoptera:Lycaenidae) and ants (Hymenoptera: Formicidae). J Entomol Soc South Afr 46:341-366

Hölldobler B (1971) Communication between ants and their guests. Sci Am 224:86-93

Hölldobler B, Carlin NF (1987) Anonymity and specificity in chemical communication signals of social insects. J Comp Physiol A 161:567-581
Howard RW, McDaniel CA, Blomquist GJ (1980) Chemical mimicry as an integrating mechanism: cuticular hyrdocarbons of a termitophile and its host. Science 210:431-433

Jermy $\mathrm{T}$ (1986) The role of experience in the host selection of phytophagous insects. In: Chapman RF, Bernays EA, Stoffolano JG (eds) Perspectives in chemoreception and behaviour. Springer, Berlin Heidelberg New York, pp 143-157

Küpper G, Schwammberger KH (1995) Parasitism in bumble bees (Hymenoptera:Apidae) - observations of Psithyrus sylvestris in Bombus pratorum nests. Apidologie 26:245-254

Larson FK (1986) Increased nest density of the digger wasp Bombix rostrata as a reponse to parasites and predators. Entomol Gener 12:71-75

Lotem A, Nakamura H, Zahavi A (1992) Rejection of cuckoo eggs in relation to host age: a possible evolutionary equilibrium. Behav Ecol 3:126-132

Lotem A, Nakamura H, Zahavi A (1995) Constraints on eggs discrimination and cuckoo-host co-evolution. Anim Behav 49: $1185-1209$

Lutermann H (1997) Zur Fortpflanzungsbiologie von Parastizopus armaticeps Peringuey. Das Verhalten und der Reproduktionserfolg unter besonderer Berücksichtigung der Vergesellschaftung mit Eremostibes opacus Koch. MSc Thesis, University of Bonn

May RM, Robinson SK (1985) Population dynamics of avian brood parasitism. Am Nat 126:475-484

McCorquodale DB (1986) Digger wasp (Hymenoptera:Sphecidae) provisioning flights as a defence against a nest parasite, Stenotainia trilineata (Diptera:Sarcophagidae). Can J Zool 64:1620-1627

Moritz RFA, Kirchner WH, Crewew RM (1991) Chemical camouflage of the deaths head hawkmoth (Acherontia atropos L.) in honeybee colonies. Naturwissenschaften 78:179-182

Müller CB, Schmid-Hempel P (1992) Correlates of reproductive success among field colonies of Bombus lucorum - the importance of growth and parasites. Ecol Entomol 17:343-353

Papaj DR (1986) Interpopulation differences in host preference and the evolution of learning in the butterfly Battus philenor. Evolution 40:518-530

Pukowski E (1933) Ökologische Untersuchungen an Necrophorus F. Z Morph Ökol Tiere 27:518-586

Rasa OAE (1994) Parabiosis in desert tenebrionids. Ethology 98:137-148

Rasa OAE (1996) Interspecific association in desert tenebrionid beetle: a cleptoparasite does not affect the host's reproductive success but that of its offspring. Naturwissenschaften 83:575577

Rasa OAE (1997) Aggregation in a desert tenebrionid beetle: a cost/benefit analysis. Ethology 103:466-487

Rasa OAE (1998a) To stay or leave? Decision rules for partner species relocation in two symbiotic pairs of desert beetles. Anim Cognit 1:47-54

Rasa OAE (1998b) Biparental investment and reproductive success in subsocial desert beetle: the role of maternal effort. Behav Ecol Sociobiol 43:105-113

Rasa OAE (1999) Division of labour and extended parenting in a desert tenebrionid beetle. Ethology 105:37-56

Rödder B (1995) Zur Fortpflanzungsbiologie von Eremostibes opacus Koch: der Einfluss ökologischer Faktoren auf die Fitness, unter besonderer Berücksichtigung der Vergesellschaftung mit Parastizopus armaticeps Peringuey. MSc Thesis, University of Bonn

Rohwer S, Spaw CD (1988) Evolutionary lag versus bill-size constraints: a comparative study of the acceptance of cowbird eggs by old hosts. Evol Ecol 2:27-36

Rosenheim JA (1987) Host location and exploitation by the cleptoparasitic wasp Argochrysis armilla: the role of learning (Hymenoptera:Chrysididae). Behav Ecol Sociobiol 21:410-416

Rosenheim JA (1990) Density-dependent parasitism and the evolution of aggregated nesting in the solitary Hymenoptera. Ann Entomol Soc Am 83:277-286 
Røskaft E, Moksnes A, Stokke BG, Bicík V, Moskák C (2002) Aggression to dummy cuckoos by potential european cuckoo hosts. Behaviour 139:613-628

Rothstein SI (1974) Mechanisms of avian egg recognition: possible learned and innate factors. Auk 91:796-807

Schmidt-Eisenlohr L (1998) Mechanismen der FuttervorratsSchätzung brutpflegender Weibchen von Parastizopus armaticeps Peringuey. MSC Thesis, University of Bonn

Schwammberger KH (1998) Effects of the social parasite Sulcopolistes atrimandibularis on the population of its host Polistes biglumis (Hymenoptera:Vespidae). Entomol Gener 23:153-167

Sledge MF, Dani FR, Cervo R, Dapporto L, Turillazzi S (2001) Recognition of social parasites as nest-mates: adoption of colony-specific host cuticular odours by the paper wasp parasite Polistes sulcifer. Proc R Soc Lond B 268:2253-2260
Taylor RJ (1974) Role of learning in insect parasitism. Ecol Monogr 44:89-104

Trumbo ST, Kon M, Sikes D (2001) The reproductive biology of Ptomascopus morio, a brood parasite of Nicrophorus. J Zool 255:543-560

Van der Meer RK, Wojcik DP (1982) Chemical mimicry in the myrmecophilous beetle Myrmecaphodeus excavaticollis. Science 218:806-808

Wcislo WT (1984) Gregarious nesting of a digger wasp as a 'selfish herd' response to a parasitic fly (Hymenoptera: Sphecidae; Diptera: Sarcophagidae). Behav Ecol Sociobiol 15:157-160

Wilson EO (1971) The insect societies. Harvard University Press, Harvard 